The research program of the Center for Economic Studies (CES) produces a wide range of theoretical and empirical economic analyses that serve to improve the statistical programs of the U.S. Bureau of the Census. Many of these analyses take the form of CES research papers. The papers are intended to make the results of CES research available to economists and other interested parties in order to encourage discussion and obtain suggestions for revision before publication. The papers are unofficial and have not undergone the review accorded official census Bureau publications. The opinions and conclusions expressed in the papers are those of the authors and do not necessarily represent those of the U.S. Bureau of the Census. Republication in whole or part must be cleared with the authors.

\title{
A FLEXIBLE TEST FOR AGGLOMERATION ECONOMIES IN TWO U.S. MANUFACTURING INDUSTRIES
}

\author{
by \\ Edward J. Feser * \\ University of North Carolina at Chapel Hill
}

CES 04-14 August, 2004

All papers are screened to ensure that they do not disclose confidential information. Persons who wish to obtain a copy of the paper, submit comments about the paper, or obtain general information about the series should contact Sang $V$. Nguyen, Editor, Discussion Papers, Center for Economic Studies, Washington Plaza II, Room 206, Bureau of the Census, Washington, DC 20233-6300, (301-763-1882) or INTERNET address snguyen@ces.census.gov. 


\title{
A FLEXIBLE TEST FOR AGGLOMERATION ECONOMIES IN TWO U.S. MANUFACTURING INDUSTRIES
}

\author{
Edward J. Feser \\ Assistant Professor \\ Department of City and Regional Planning \\ CB 3140, New East Building \\ University of North Carolina \\ Chapel Hill, NC 27599-3140 \\ Tel: (919) 962-4768 Fax: (919) 962-5206 \\ E-Mail: feser@email.unc.edu
}

July 2000 


\title{
A FLEXIBLE TEST FOR AGGLOMERATION ECONOMIES IN TWO U.S. MANUFACTURING INDUSTRIES
}

\begin{abstract}
This paper uses the inverse input demand function framework of Kim (1992) to test for economies of industry and urban size in two U.S. manufacturing sectors of differing technology intensity: farm and garden machinery (SIC 352) and measuring and controlling devices (SIC 382). The inverse input demand framework permits the estimation of the production function jointly with a set of cost shares without the imposition of prior economic restrictions. Tests using plantlevel data suggest the presence of population scale (urbanization) economies in the moderate- to low-technology farm and garden machinery sector and industry scale (localization) economies in the higher technology measuring and controlling devices sector. The efficiency and generality of the inverse input demand approach are particularly appropriate for micro-level studies of agglomeration economies where prior assumptions regarding homogeneity and homotheticity are less appropriate.
\end{abstract}

Keywords: Agglomeration economies; localization; urbanization; production functions JEL Classification: R10; R12; R30 


\section{A FLEXIBLE TEST FOR AGGLOMERATION ECONOMIES IN TWO U.S. MANUFACTURING INDUSTRIES}

\section{INTRODUCTION}

Much of the recent empirical agglomeration economies literature is concerned with two fundamental questions. The first is whether agglomeration economies are due to urbanization (urban size) or localization (industry size) effects (Nakamura, 1985; Henderson, 1986; Moomaw, 1988). Although the debate has tended to take on an "either-or" tone, a review of existing work suggests that the source of the economies varies by sector. One key dimension along which such variation may occur is technology intensity. Urbanization economies are often traced to the greater availability of physical infrastructure in larger urban areas, larger pools of workers with general skills or entrepreneurial talent, or the presence of wholesaling operations (Hoover 1937; Isard, 1956). By contrast, localization economies are tied to the availability of specialized infrastructure, facilities, and labor, e.g., inputs and repair facilities specific to the industry in question and specialized labor pools of the Marshallian variety. Thus, we might expect technology- or knowledge-intensive industries that utilize highly specialized equipment, expertise, and knowledge to benefit more from proximity to other enterprises in their same industry (localization effects) than low to moderate technology sectors would, other things equal. Lower technology industries producing less knowledge-intensive goods may, by contrast, benefit relatively more from general advantages in large urban environments (urbanization effects) since

I would like to thank Harvey Goldstein, Michael Luger, Emil Malizia, and two anonymous reviewers for their helpful comments and suggestions. The research in this paper was conducted while I was a research associate at the Center for Economic Studies, U.S. Bureau of the Census. Research results and conclusions expressed are mine and do not necessarily indicate concurrence by the Bureau of the Census or the Center for Economic Studies. 
such industries typically require workers of less specialized skill, as well as technology and equipment of more common application.

The second fundamental question concerns the appropriate methodology for production function studies of agglomeration economies. In an analysis of agglomeration economies in the U.S. food processing industry, Sveikauskas, Gowdy, and Funk (1988) demonstrate the utility of a version of the translogarithmic production function developed by Chan and Mountain (1983) that permits the differentiation between technical change and economies of scale. The Chan-Mountain framework is particularly effective for addressing the simultaneity between industry scale and city size productivity advantages that is an issue at the macro level of analysis, i.e., that "industry size is large relative to population size precisely where production conditions are most favorable" (Sveikauskas, Gowdy, and Funk, p. 186). City size is modeled as technical change while industry size productivity effects are revealed through a homogeneity parameter of the aggregate production function. While the Chan-Mountain production function is an improvement over more traditional translog specifications that assume constant returns to scale, it is based on the properties of homogenous functions and therefore still imposes the assumption of homotheticity. It is therefore still more restrictive than one would prefer.

This paper addresses both the urbanization/localization debate and the methodology issue by using the highly flexible inverse input demand framework of Kim (1992) in a plant-level test for the presence of economies of urban and industry size in two U.S. manufacturing sectors of differing technology intensity: farm and garden machinery (SIC 352) and measuring and controlling devices (SIC 382). Kim's methodology treats homotheticity as a testable proposition and is also more efficient than Chan-Mountain since it does not introduce an additional scale 
parameter. It is especially useful in establishment- or firm-level studies where both industry and urban size can be modeled as technical change and where a priori assumptions regarding homotheticity and homogeneity are less convincing. Restrictions on production (homotheticity, homogeneity, constant returns) may be tested in a straightforward manner, thereby permitting more confident interpretation of any findings with respect to spatial economies. Because urbanization and localization effects enter the production function in strictly comparable forms, a more direct evaluation of the urbanization vs. localization question is possible.

The principal data for the study, confidential micro-data from the Census of Manufactures, permits two other important improvements on existing production studies of agglomeration. First, output is measured as gross output of the establishment rather than the more common value-added or total value of production at the level of the industry (e.g., see Sveikauskas 1975 and Moomaw 1985, among others). Use of value-added not only imposes restrictive assumptions (e.g., that input prices are the same everywhere), but as measured in the Census of Manufacturers, it excludes services (both purchased externally and transferred between units of the same firm). Ciccone and Hall (1996) note that studies using Census of Manufactures value-added typically overstate the productivity advantage of large cities or dense areas. Establishments in such places tend to out-source or rely on transferred services to a greater degree than establishments in smaller, less diverse regions. The total value of output at the industry level (measured as the total value of shipments in the Census of Manufactures) doublecounts inputs traded within the industry (Ciccone and Hall 1996).

The second advantage afforded by the confidential Census micro-data is that plants can be geo-coded to counties and population and employment can be summed for relevant commuting 
sheds. Much greater spatial variation in population and industry size is thereby admitted, improving the robustness of the results. Industry-level studies, by contrast are restricted to highly aggregate geographic units within which urban and industry scale are assumed everywhere the same.

The two study sectors differ in their degree of technology-intensity and geography. The final market, durable goods farm and garden machinery industry $(1,775$ establishments and \$14.8 billion in sales in 1992), produces a wide range of low- to moderate-technology goods (from hedge trimmers, seeders, and lawn tractors to hay balers, portable corrals, and farm elevators). Plants producing farm machinery and equipment constitute 92 percent of the sector's establishments; lawn and garden equipment manufacturers make up the remaining 8 percent. Leading states in terms of employment in the sector are in the Midwest and South: Illinois, Iowa, Nebraska, Georgia, South Carolina, Tennessee, and Wisconsin. No single metropolitan area dominates other locations. Measuring and controlling devices (4,726 establishments, $\$ 34.4$ billion in sales in 1992) is a high technology producer durable sector and an important supplier to the aircraft, motor vehicles, search and navigation equipment, guided missiles and space vehicles, and refrigeration and heating equipment sectors. Products include optical instruments, automated controls, fluid meters, and laboratory apparatus and equipment. The sector is highly clustered in larger metropolitan areas along the east and west coasts (in California, New York, and Massachusetts) and to a lesser degree in the Midwest (Michigan, Illinois, and Ohio) and Southwest (Texas).

The results indicate that urbanization economies cannot be ruled out in the farm and garden machinery industry while localization economies appear binding in the measuring and 
controlling devices sector. The findings are consistent with expectations as well as previous empirical studies. The final section of the paper emphasizes, however, that any finding based on measures of population and industry scale must be interpreted with cautiously, absent any direct information on the underlying determinants of the urbanization and localization effects.

\section{A FLEXIBLE PRODUCTION FUNCTION APPROACH}

The following translogarithmic production function describes plant-level manufacturing activity in the study sectors, where the $X_{i}$ index inputs and the $A_{m}$ are a set of agglomeration indices (e.g., industry and urban size as proxy indicators of localization and urbanization):

$$
\begin{aligned}
\ln Y & =\alpha_{0}+\sum_{i} \alpha_{i} \ln X_{i}+\sum_{m} \xi_{m} \ln A_{m}+\frac{1}{2} \sum_{i} \sum_{j} \beta_{i j} \ln X_{i} \ln X_{j} \\
& +\sum_{i} \sum_{m} \gamma_{i m} \ln X_{i} \ln A_{m}+\frac{1}{2} \sum_{m} \sum_{n} \delta_{m n} \ln A_{m} \ln A_{n}
\end{aligned}
$$

Most applications of the translog utilize duality theory to estimate the cost function, or, more often, the set of associated factor-share (input demand) functions (Chung, 1994; Hamermesh, 1993; Chambers, 1988). The latter are derived from the cost function via Shephard's lemma, and, as long as technical change is assumed Hicks-neutral, provide sufficient information to calculate the parameters that are typically of primary interest. The cost (production) function may be estimated by itself using ordinary least squares or jointly with the cost share equations if factor augmenting technical change is assumed. Joint estimation of the cost share equations-or estimation of the share equations along with the cost or production function-has the important advantage of improving efficiency and reducing multicollinearity. 
Under constant returns to scale (CRTS) and competitive input markets, the factor demands are equivalent to simple cost shares. Production studies jointly estimating cost shares of this form are criticized by Chan and Mountain (1983) who seek to estimate, rather than assume, the degree of returns to scale. They propose a production function $Y=F(X, T)$, where $Y$ is homogenous of degree $\theta$ so that $F(X, T) k^{\theta}=F(k X, T), k$ is a constant, and the following cost share equations result:

$$
\frac{\partial \ln Y}{\partial \ln X_{i}} \frac{1}{\theta}=\frac{W_{i} X_{i}}{C}=S_{i}
$$

where $W_{i}, X_{i}$, and $S_{i}$ are the price, quantity, and cost share of the $i$ th input, respectively, and $C$ is total cost. Returns to scale are given by the homogeneity parameter $\theta$ in the joint estimation of the modified share equations and the production function. Sveikauskas, Gowdy and Funk (1988) implemented the Chan-Mountain methodology in a regional cross-sectional agglomeration economies context. They interpreted the homogeneity parameter as a measure of localization economies since their analysis was conducted for the food processing industry (SIC 20) in aggregate; they did not include a variable measuring regional industry size. The Chan-Mountain approach is an improvement over the traditional methodology, particularly for micro-level studies where the homogeneity parameter measures internal scale economies at the plant level. While constant returns is often regarded to hold at the level of the industry, several studies have found increasing returns more common at the establishment level (Mountain, 1986; Aivanzian et al., 1987; Ke, 1995). 
At the same time, the Chan-Mountain methodology is based on the properties of homogenous functions and therefore still imposes the assumption of homotheticity. A useful alternative is more general framework of Kim (1992), which, by deriving the cost share equations directly from the input demands from the first order conditions of the profit maximization decision, makes homotheticity a testable proposition. Given a production function $Y=f(\boldsymbol{X})$ where $\boldsymbol{X}$ is a vector of inputs, the firm maximizes profits where $P$ is the price of output and $\boldsymbol{W}$ is a vector of input prices. From the standard first order conditions and the assumption of competitive output markets, the following factor share equations result (see Kim):

$$
\left(\sum_{i} \frac{\partial \ln Y}{\partial \ln X_{i}}\right)^{-1}\left(\frac{\partial \ln Y}{\partial \ln X_{i}}\right)=\frac{W_{i} X_{i}}{C}=S_{i}
$$

where $C$ is total costs $(\boldsymbol{W} \boldsymbol{X})$. Differentiating (1) according to (3) yields

$$
\frac{\alpha_{i}+\sum_{j} \beta_{i j} \ln X_{j}+\sum_{m} \gamma_{i m} \ln A_{m}}{\sum_{i} \alpha_{i}+\sum_{i} \sum_{j} \beta_{i j} \ln X_{j}+\sum_{i} \sum_{m} \gamma_{i m} \ln A_{m}}=S_{i}
$$

The translog parameters may be derived from a joint estimation of (1) and (4).

The nature of the cost share equations provides some intuition about the way in which this production system differs from the usual derivation of cost shares from the production function. The usual profit maximization conditions $W_{\mathrm{i}} / P=\partial Y / \partial X_{i}$ measure the price the firm is willing to pay to obtain a given quantity of an input at a given output price. Equations (1) and (4) therefore represent the production function along with its set of (inverse) input demand functions (Kim 1992). 
The production function (1) is homothetic if $\sum_{j} \beta_{i j}=0$. It is homogenous of degree $\theta$, if, in addition, $\sum_{i} \alpha_{i}=\theta$ and $\sum_{i} \gamma_{i m}=0$. Under linear homogeneity or constant returns to scale (CRTS), $\sum_{i} \alpha_{i}=1$, and the denominator of (4) sums to unity, thus reducing to the more commonly studied cost share equations outlined above. $\sum_{i} \partial \ln Y / \partial \ln X_{i}$ gives variable returns to scale while the degree of homogeneity $\theta$ is given by $\sum_{i} \alpha_{i}$. The Kim production system is thus an improvement over the both the Chan-Mountain and standard CRTS methodology because it constitutes the more general case and does not introduce the returns to scale parameter as an additional parameter requiring estimation within the general system. Nested empirical tests for homotheticity, homogeneity, and constant returns to scale are easily performed.

\section{AGGLOMERATION ECONOMIES IN TWO SECTORS}

In the following application of flexible translog system, the agglomeration indices, $A_{m}$, are traditional conceptualizations of urbanization and localization economies as measured by regional population and industry size, respectively. Plant-level data for the farm and garden machinery and measuring and controlling devices industries are from the 1992 Census of Manufactures as contained in the Longitudinal Research Database (LRD) of the U.S. Bureau of the Census. All variables are defined below following a brief description of the modeling procedure. 


\section{Estimated Model and Procedures}

The following production function and its cost share equations are estimated jointly:

$$
\begin{aligned}
\ln Y= & \alpha_{0}+\alpha_{k} \ln K+\alpha_{l} \ln L+\alpha_{e} \ln E+\alpha_{m} \ln M+\frac{1}{2} \beta_{k k}(\ln K)^{2}+\beta_{k l} \ln K \ln L+ \\
& \beta_{k e} \ln K \ln E+\beta_{k m} \ln K \ln M+\frac{1}{2} \beta_{l l}(\ln L)^{2}+\beta_{l e} \ln L \ln E+\beta_{l m} \ln L \ln M+ \\
& \frac{1}{2} \beta_{e e}(\ln E)^{2}+\beta_{e m} \ln E \ln M+\frac{1}{2} \beta_{m m}(\ln M)^{2}+\xi_{u} \ln U R B+ \\
& \gamma_{k u} \ln K \ln U R B+\gamma_{l u} \ln L \ln U R B+\gamma_{e u} \ln E \ln U R B+\gamma_{m u} \ln M \ln U R B+ \\
& \xi_{c} \ln L O C+\gamma_{k c} \ln K \ln L O C+\gamma_{l c} \ln L \ln L O C+\gamma_{e c} \ln E \ln L O C+ \\
& \gamma_{m c} \ln M \ln L O C+\frac{1}{2} \delta_{u u}(\ln U R B)^{2}+\delta_{u c} \ln U R B \ln L O C+\frac{1}{2} \delta_{c c}(\ln L O C)^{2}
\end{aligned}
$$

where $Y, K, L, E$, and $M$ are output, capital, labor, energy, and materials, respectively, and $U R B$ and $L O C$ are regional population and industry size variables, respectively. The urbanization and localization effects enter the production function in factor-augmenting form.

Four specifications of the production function are estimated and a series of nested tests performed: 1) the production function and cost share equations are estimated without any restrictions, three tests for Hicks-neutrality of the urbanization and localization effects are carried

out $\left(\gamma_{i p}=0, \gamma_{i c}=0, \gamma_{i p}=\gamma_{i c}=0\right)$, and homotheticity of the production function is tested against the unrestricted function; 2) homotheticity is imposed and homogeneity of degree $\theta$ is tested against the homothetic function; 3) homogeneity is imposed and constant returns to scale is tested against the homogenous function; 4) constant returns is imposed.

Equations (4) and (5) constitute a nonlinear multivariate regression system. Additive disturbances are appended to each of the equations and assumed to have a multivariate normal distribution with zero mean vector and constant covariance, but contemporaneous correlation 
among equations is allowed. The iterative nonlinear seemingly unrelated regression method is used for estimation. Because the cost shares sum to unity, it is necessary to estimate $n$ - 1 share equations. Iterated seemingly unrelated regression estimates are asymptotically equivalent to maximum likelihood estimates and are invariant to the omitted share equation (Berndt, 1990; Greene, 1993). All hypothesis tests are conducted using the likelihood ratio statistic defined in Gallant (1987). ${ }^{1}$ Breusch-Pagan tests under alternative assumptions about the form of possible heteroscedasticity of the errors were negative and normality of the residuals was strongly confirmed based on Mardia's skewness and kurtosis tests, the Shapiro-Wilk test, and the Kolmogorov-Smirnov test. Adjusted R-squared values are also reported for each estimated equation, though primarily for descriptive purposes. In the present application, they vary little across different models and thus are of little use in judging alternative specifications. Since Berndt's (1990) generalized system R-squared statistic for the estimated equations also varied little across specifications (it ranged between 0.995 and 0.998), it is not reported in the tables.

\section{Variables and Data}

The LRD reports 1,775 establishments and 86,200 employees in the farm and garden machinery sector in 1992. The measuring and controlling devices sector was comprised of 4,726 establishments and 274,400 workers in the same year. However, in any given census year, a significant number of the smaller plants in the Census sample frame are exempted from filing requirements. The only actual data obtained for such establishments (which are dubbed

${ }^{1}$ Tests based on the likelihood ratio statistic were compared to those based on the lagrange multiplier and Wald test statistics. The likelihood ratio and lagrange multiplier tests generated similar qualitative conclusions, while few null hypotheses were accepted under the Wald test. Results using the Wald test seem implausible (especially given estimated internal scale parameters). 
"administrative records") are name and address, payroll, and gross business receipts as reported by the Internal Revenue Service and Social Security Administration. Other key census statistics are imputed using industry average ratios to payrolls and sales. In some circumstances, particularly in the preparation of published summary statistics, the use of administrative records is appropriate. However, since the validity of the production function depends strongly on the quality of the underlying data, administrative records are excluded from the analysis reported here, effectively reducing the sample sizes for each industry by about half.

Excluding administrative records from the samples means that estimation results do not strictly apply to the full farm and garden machinery and measuring and controlling devices industries. For the sake of convenience only, findings are described with respect to the two industries without the caveat that the smallest producers are not included in the samples. The reader must bear in mind the specific composition of the samples while also noting that they are not composed of strictly large firms. The median size plants in the SIC 352 and 382 samples employs 27 and 31 workers, respectively. Twenty-five percent of the establishments in the SIC 352 and 382 samples employ fewer than 13 and 15 workers, respectively.

The following sections describe the measurement of the conventional factors in the production function. Except where noted specifically, all data are from the LRD.

Output. Output at plant $i, Y_{i}$, is defined as the total value of shipments adjusted for inventories and work in process:

$$
Y_{i}=T V S_{i}+\left(W I E_{i}-W I B_{i}\right)+\left(F I E_{i}-F I B_{i}\right)
$$

where $T V S_{i}$ is the total value of shipments, $W I E_{i}$ is work in process at the end of the year, WIB is work in process at the beginning of the year, $F I E_{i}$ is the end-year value of finished product 
inventories, and $F I B_{i}$ is the value of finished product inventories at the beginning of the year. A few records in each industry for which output was reported as zero were excluded from the sample.

Capital. The most widely accepted approach to constructing a measure of capital input is the perpetual inventory method. However, the need to observe sample units over time represents a significant problem for micro-level applications since sample sizes are reduced dramatically. In addition, producers which are observed over long periods are typically the very largest manufacturers and thus are not representative of the majority of producers in their industries (given the skewed nature of the plant size distribution). Such problems become extreme in the context of this study, where good spatial variation, a reasonable distribution of small to large manufacturers, and a large sample size are required.

As an alternative, a proxy for capital services input is employed that is defined as the sum of the book values of capital assets and capitalized rentals:

$$
K_{i}=\left(B A E_{i}+M A E_{i}\right)+\left(C B R_{i}+C M R_{i}\right)
$$

where $B A E_{i}$ is the value of building assets at the end of the year, $M A E_{i}$ is the value of machinery assets at the end of the year, and $C B R_{i}$ and $C M R_{i}$ are capitalized building and machinery rentals. The latter are derived by dividing rental expenditures for each asset category by two-digit SIC capital prices from the Bureau of Labor Statistics. Defining capital services in terms of gross stocks, or the sum of building and machinery assets, has been demonstrated by Doms (1992) to represent a reasonable approximation in micro-level research using the LRD. The approach has generated plausible results in a wide range of studies using Census micro data (Nguyen and Reznek, 1990; Dunne and Roberts, 1992; Doms and Dunne, 1993; Martin, McHugh, and 
Johnson, 1993). The inclusion of capitalized rentals in the simple measure of stocks, however, has been attempted only infrequently to date by researchers using the LRD (Kokkelenberg and Nguyen, 1989; Gort, Bahk and Wall, 1991). For the study plants in SICs 352 and 382, the shares of capitalized building and machinery rentals to the total stock average around 17 percent; for some establishments the shares are much higher. Therefore, it is important that they be included not only in the stock measure, but also in the measure of capital costs.

Labor. Because the LRD reports hours only for production workers, total worker hours at establishment $i$ are estimated as $L_{i}=\left(W_{p i}+W_{n i}\right) / P_{l p i}$, where $W_{p i}$ and $W_{n i}$ are production and non-production worker wages and salaries, respectively, and $P_{l p i}$ is the production worker average hourly wage. The method effectively assumes that the average wages of production and nonproduction workers are equivalent. An alternative would be to assume a 2,000 hour work year for each non-production employee (the LRD reports employment, but not hours, of nonproduction workers), but that would neglect the fact that many non-production workers are parttimers. Moreover, fluctuations in employment over the course of the year are reflected in total wage payments but not employment, since the latter is measured for the week of March 12 for the given Census year. Based on previous work with the LRD, Nguyen and Reznek (1990) suggest the estimate of total worker hours is an improvement over the use of employment as the labor quantity measure.

Energy and Materials. The annual volume of purchased electricity in kilowatt hours and total expenditures for fuel and electricity from the LRD were used along with 1992 energy cost and price information from the Energy Information Administration's State Energy Price and Expenditure Report (SEPER) to develop the following plant-specific measure of energy usage: 


$$
E_{i s}=E Y_{i}+\sum_{g} \frac{C F_{i}\left(C F_{g s} / T C_{s}\right)}{P_{g s}}, \quad T C_{s}=\sum_{g} C_{g s}
$$

where $E_{i s}$ is total energy usage in British thermal units (Btu) by plant $i$ in state $s, E Y_{i}$ is electricity consumption (Btu) by plant $i, C F_{i}$ total fuel expenditures by plant $i, C F_{g s}$ is total expenditures for fuel $g$ ( $g=$ coal, natural gas, petroleum) by the industrial sector in state $s$, and $P_{g s}$ is the per Btu average price of fuel $g$ in state $s$. The numerator of the term in the summation represents a weighting of plant fuel expenditures based on typical fuel consumption patterns in the establishment's home state. Since the LRD reports both the quantity and cost of electricity, it is possible to construct a plant-level price of electricity that may be compared to state prices reported in SEPER, thereby providing some indication of the validity of using state prices to develop quantity figures. Results from that comparison showed that state-level electricity prices provide a reasonable match to the plant-specific electricity prices, though the match was better for the all-sector state average price than for the industrial sector price. Therefore, all sector average prices are used in the construction of $E_{i s}{ }^{2}$

Materials. Materials input for plant $i, M_{i}$, is the sum of expenditures for materials and contract work as reported in the LRD.

Costs. Capital costs are composed of two components. The first is rental expenditures for buildings and machinery as reported directly in the LRD. The second is expenditures for building and machinery assets. The latter are derived by multiplying reported end-of-year assets

2 Approximately 120 plants in SIC 382 and 50 plants in SIC 352 did not report data for fuels or electricity. The missing data were estimated from a regression of $E_{i s}$ on other conventional inputs in a CobbDouglas specification for plants with non-missing data (results available on request). In initial estimations of the production function, an interaction term was included to test for differences between plants with and without estimated energy data. No significant differences were found. 
by unpublished Bureau of Labor Statistics structures and equipment rental prices for SICs 35 and 38. Total labor costs are the sum of salaries, wages, and voluntary and required supplemental labor costs. Energy costs are the sum of fuels and electricity expenditures. The total cost of production is the sum of capital, labor, material and energy expenditures.

Urbanization and Localization. The LRD reports the physical location of each manufacturing plant by county. Urbanization $(U R B)$ is measured as the total population within a 50 mile commuting shed of the plant. A county's population is assigned to a given plant's commuting shed if its population centroid is within 50 miles of the study plant's home county population centroid. Estimated county population figures for 1992 are from the Bureau of Economic Analysis. Localization $(L O C)$ is measured similarly as the total employment in the respective study industry for each plant's 50 mile shed. Table 1 reports descriptive statistics for the two study industries as well as several additional performance and wage indicators.

[Table 1 near here]

\section{RESULTS}

The IZEF parameter estimates from the four different model specifications are reported in Tables 2 and 3, along with their asymptotic standard errors and t-statistics. Monotonicity and convexity are satisfied for each estimated function. ${ }^{3}$ Results of the likelihood ratio tests on the six hypotheses are reported in Table 4. Linear homogeneity could not be rejected at conventional significance levels for the farm and garden machinery sector. Constant returns to scale nearly hold in the measuring and controlling devices industry as well; there is only weak evidence that

\footnotetext{
${ }^{3}$ Monotonicity was checked at each data point. Convexity, which is ensured if the bordered Hessian matrix of first and second derivatives is negative definite, was checked at the means of the sample.
} 
homogeneity of degree $\theta$ is the more appropriate specification. The results suggest that the assumptions of homogeneity and constant returns so often imposed for convenience in regionallevel studies of business agglomeration economies may not be excessively restrictive, at least for the two samples here. The findings also add to a few studies that have found constant returns to scale at the microeconomic level (Martin, McHugh, and Johnson 1993; Ngyuen and Reznek 1990).

[Tables 2, 3, and 4 near here]

It is important to note that the results do not imply that the use of a more flexible translog system is unnecessary. First, it is preferable to test rather than assume a production restriction if the sample size and data permit. Kim's (1992) framework provides an efficient way of doing that. Analysis of other industries may very well yield a different result. Second, the Kim framework provides a means of examining the sensitivity of the results to different production specifications. In contrast to the parameters on the conventional inputs, there is significant variation in some of the population and industry scale parameters and asymptotic standard errors across the four technical specifications. Several parameters in the farm and garden machinery sample become more significant as increasingly restrictive specifications are imposed $\left(\boldsymbol{\gamma}_{l c}, \gamma_{m p}, \boldsymbol{\gamma}_{l p}, \boldsymbol{\gamma}_{k p}\right)$, a direct result of the improved efficiency afforded by incorporating the additional information on the technology derived from the hypothesis tests. The degree of variation in localization and urbanization parameters in the measuring and controlling devices sample is even greater. The factor augmenting effects with respect to urbanization come in and out of significance, and the 
magnitudes of some estimates change dramatically from the nonhomothetic to CRTS specifications. $^{4}$

Turning to the neutrality of the spatial technology effects, the results are somewhat ambiguous. A simple examination of individual parameter estimates and their approximate standard errors provides strong evidence in favor of factor augmentation of both types of agglomeration effect for SIC 352 and mild evidence of the same for SIC 382. Different specifications of the formal likelihood ratio tests yield alternative inferences. For farm and garden machinery, individual tests find evidence of factor augmentation only for urbanization economies, and then only at the 5 percent level. For measuring and controlling devices, individual tests reject the factor augmenting form for both types of spatial effect at conventional significance levels. However, when the neutrality of urbanization and localization effects are tested jointly, there is evidence that spatial economies are factor augmenting for both farm and garden machinery (at the 5 percent significance level) and measuring and controlling devices (at the 1 percent level). The joint test, in conjunction with the parameter estimates, favors retaining the less restrictive factor augmenting form of the agglomeration economies across the four estimated models.

\section{Urbanization and Localization Economies}

Output elasticities with respect to the conventional inputs and industry and urban scale are reported, along with internal returns to scale, in Table 5. For both industries, variations in the quantity of labor and materials have a greater impact on production than variations in labor and capital. Output in the measuring and controlling devices sector is somewhat more elastic with respect to capital and labor than in the farm and garden machinery industry. The conventional

\footnotetext{
${ }^{4}$ An extensive investigation of the substitution properties of the two sectors is available upon request.
} 
output elasticities vary little by technology specification, as is expected given the little variation in the underlying parameter estimates noted above. Very slight increasing returns to scale are suggested for both sectors, although the likelihood ratio test failed to reject the CRTS model for either industry at the 99 percent significance level. Even if CRTS is rejected for SIC 382 using a lower level of significance, the magnitude of the returns is small (at 1.018).

[Table 5 near here]

For the sample of establishments in the farm and garden machinery industry, each doubling of regional population yields an approximately 1.9 to 2.1 percent increase in output, depending on the model assumptions. Local industry scale appears to confer no significant productivity differential. In the measuring and controlling devices sample, a doubling of industry scale is associated with higher productivity; the output elasticity is in the range of 2.3 to 2.6 percent, depending on the model specification. There is weak evidence (not statistically significant at conventional levels), that population scale has an adverse effect on productivity; i.e. that urbanization is a proxy for diseconomies in the measuring and controlling devices sector.

Comparisons of the results to those in the literature are interesting, though only suggestive due to fundamental differences in methodology. Åberg (1973) found elasticities of labor productivity with respect to population in the range of 0.009 to 0.039 using data for disaggregated Swedish manufacturing industries. Moomaw's (1981) population elasticity for SIC 35 is 0.022 and highly significant while the elasticity for SIC 38 is 0.029 and statistically insignificant. Using data for sixteen Japanese industries, Nakamura (1985) found an unweighted average elasticity of labor productivity with respect to population of 0.034 , and an average localization elasticity of 0.045 . Henderson (1986) found that localization effects are stronger for 
most U.S. industries, though the magnitudes are difficult to evaluate in comparison to this research since they depend on the value of SMSA employment. His total factor productivity urbanization elasticities for SIC 35 are 0.033 (OLS) and 0.020 (2SLS), though neither is significant; he did not produce an estimate for SIC 38. Sveikauskas, Gowdy and Funk (1988) report that output in the food products industry increases 1 to 2 percent with each doubling of the population. Moomaw (1988) found neither urbanization or localization economies for SIC 35 and only localization effects for SIC 38.

\section{SUMMARY}

Kim's methodology, in combination with establishment-level data, permits a highly flexible and attractive test for urbanization and localization economies. The results cannot rule out the presence of urbanization effects in the lower-technology farm and garden machinery industry and localization economies in the higher technology measuring and controlling devices sector. The findings are broadly consistent both with previous empirical studies of agglomeration economies and the growing literatures on Marshallian industrial districts, industry clusters, and regional innovation systems (see Cooke and Morgan 1998; Steiner 1998; Cooke et al. 2000), which highlight the advantages of spatial clustering, particularly for smaller, technology-intensive businesses. Clearly, more study is necessary for multiple sectors to confirm whether there is a consistent relationship between technology-intensity and urbanization/localization effects.

At the same time, any findings of urbanization and/or localization economies that are based on the use of generalized proxy measures of urban and industry scale must be interpreted very cautiously. The present study assumes, consistent with the literature, that population scale is 
a sufficient proxy measure for theoretical urbanization economies while industry size is a valid indicator for theoretical localization economies. But to see the importance of the assumption consider only one example, i.e. Isard's (1956) hypothesis that proximity to input suppliers is a key an explanation for localization economies. Because the degree to which industries' input supplies are derived from their own industry varies widely (as even a cursory examination of the national input-output table demonstrates), it is plausible that the empirical finding of population size effects in the farm and garden machinery industry cannot, in fact, be traced to the general advantages of urban locations. Rather, the underlying determinant of the spatial externality (in this single example, proximity to input suppliers) may correlate more closely with population scale than own-industry scale.

As an illustration, the farm and garden machinery industry is one of the most evenly distributed sectors in U.S. manufacturing; SIC 352 is represented in both rural and urban areas, as well as urban areas of widely differing size, and is clustered only to a modest degree. ${ }^{5}$ Most plants in SIC 352 are located near comparatively few other farm and garden machinery producers. However, the principal input suppliers to SIC 352 (e.g., according to U.S. input-output data: internal combustion engines, fluid power equipment, wet and dry primary batteries, and motors and generators) are more commonly located in urban areas rather than near farm and garden machinery producers. In a separate study, I found that one rough measure of proximity to input suppliers for SIC 352 is more highly correlated with population than own-industry employment (Feser 2000). Though only one example, the result emphasizes that lacking direct information on what is behind the urbanization or localization effect, any interpretation of population scale effects

\footnotetext{
${ }^{5}$ Maps of the geographic distribution of establishments are available upon request.
} 
(industry scale effects) as evidence of general urban advantages (industry specific advantages) may be tentative at best. 


\section{REFERENCES}

Åberg, Y., 1973, Regional productivity differences in Swedish manufacturing, Regional Science and Urban Economics, 3, 131-55.

Aivanzian, V.A., J.L. Callan, M.W.L. Chan, and D.C. Mountain, 1987, Economies of scale versus technological change in the natural gas transmission industry, Review of Economics and Statistics, 69, 556-61.

Berndt, E.R., 1990, The Practice of econometrics: Classic and contemporary (AddisonWesley, Reading, MA).

Chambers, R.G.,1988, Applied production analysis: A dual approach (Cambridge University Press, Cambridge).

Chan, M.W.L., and D.C. Mountain, 1983, Economies of scale and the Tornqvist discrete measure of productivity, Review of Economics and Statistics, 65, 663-7.

Chung, J.W., 1994, Utility and production functions: Theory and applications (Blackwell, Oxford).

Ciccione, A., and R.E. Hall, 1996, Productivity and the density of economic activity, American Economic Review, 86, 54-71.

Cooke, P., P. Boekholt, and F. Tödtling, 2000, The governance of innovation in Europe (Pinter, London).

Cooke, P., and K. Morgan, 1998, The associational economy (Oxford University Press, Oxford, UK).

Doms, M.E., 1992, Essays on capital equipment and energy technology in the manufacturing sector, unpublished Ph.D. thesis, University of Wisconsin at Madison. 
Doms, M.E., and T. Dunne, 1993, Energy intensity, electricity consumption, advanced manufacturing technology usage, discussion paper CES 93-9, Center for Economic Studies, U.S. Bureau of the Census, Washington, DC.

Dunne, T., and M.J. Roberts, 1992, Costs, demand, and imperfect competition as determinants of plant-level output prices, discussion paper CES 92-5, Center for Economic Studies, U.S. Bureau of the Census, Washington, DC.

Feser, E.J., 2000, The sources of local external economies, working paper, Department of City and Regional Planning, University of North Carolina at Chapel Hill.

Gallant, A.R., 1987, Nonlinear statistical models (John Wiley, New York).

Gort, M., B.H. Bahk, and R.A. Wall, 1991, Decomposing technical change, discussion paper CES 91-4, Center for Economic Studies, U.S. Bureau of the Census, Washington, DC.

Greene, W.H., 1993, Econometric analysis, (Prentice-Hall, Englewood Cliffs, NJ). Hamermesh, D.S., 1993, Labor demand (Princeton University Press, Princeton, NJ). Henderson, J.V., 1986, Efficiency of resource usage and city size, Journal of Urban Economics, 19, 47-70.

Hoover, E.M., 1937, Location theory and the shoe and leather industries (Harvard University Press, Cambridge, MA).

Isard, W., 1956, Location and space economy (Wiley, New York).

Ke, S., 1995, Beyond capital and labor: The contributions of technology and regional milieu to production and productivity growth (Garland, New York). 
Kim, H.Y., 1992, The translog production function and variable returns to scale, Review of Economics and Statistics, 74, 546-51.

Kokkelenberg, E.C., and S.V. Nguyen, 1989, Modeling technical progress and total factor productivity: A plant level example, Journal of Productivity Analysis, 1, 21-42.

Martin, S.A., R. McHugh, and S.R. Johnson, 1993, The influence of location on productivity: Manufacturing technology in rural and urban areas, Growth and Change, 24, 459-86.

Moomaw, R.L., 1981, Productive efficiency and region, Southern Economic Journal, 48, 34457.

Moomaw, R.L., 1985, Firm location and city size: Reduced productivity advantages as a factor in the decline of manufacturing in urban areas, Journal of Urban Economics, 17, 73-89.

Moomaw, R.L., 1988, Agglomeration economies: localization or urbanization? Urban Studies, 25, 150-61.

Mountain, D.C., 1986, Economies of scale versus technological change: an aggregate production function for Switzerland, Review of Economics and Statistics, 68, 707-11.

Nakamura, R., 1985, Agglomeration economies in urban manufacturing industries, a case of Japanese cities, Journal of Urban Economics, 17, 108-24.

Nguyen, S.V., and A.P. Reznek, 1990, Returns to scale in small and large U.S. manufacturing establishments, discussion paper CES 90-11, Center for Economic Studies, U.S. Bureau of the Census, Washington, DC.

Steiner, M., Ed., 1998, Clusters and regional specialisation (Pion, London). 
Sveikauskas, L, 1975, The productivity of cities, Quarterly Journal of Economics, 89, 393-413.

Sveikauskas, L., J. Gowdy, and M. Funk, 1988, Urban productivity: city size or industry size, Journal of Regional Science, 28, 185-202. 
Table 1

Descriptive statistics, study industries, 1992

\begin{tabular}{llrrrr}
\hline & & \multicolumn{2}{c}{ SIC 352 } & \multicolumn{2}{c}{ SIC 382 } \\
Variables & Description & Mean & Std. dev. & Mean & Std. dev. \\
\hline $\mathrm{Y}$ & Output (000s \$) & 16,667 & 74,559 & 12,553 & 36,314 \\
$\mathrm{~K}$ & Capital (000s \$) & $5,820.6$ & $31,992.4$ & $4,716.5$ & $17,306.8$ \\
$\mathrm{~L}$ & Labor (000s Manhours) & 215.69 & 575.62 & 275.49 & 723.82 \\
$\mathrm{E}$ & Energy (Million Btus) & 16,882 & 79,943 & 8,494 & 26,368 \\
$\mathrm{M}$ & Materials (000s \$) & $7,773.76$ & $32,946.70$ & $4,160.39$ & $12,829.74$ \\
$\mathrm{~S}_{\mathrm{k}}$ & Capital cost share & .0492 & .0246 & .0955 & .0567 \\
$\mathrm{~S}_{1}$ & Labor cost share & .3882 & .1244 & .4938 & .1271 \\
$\mathrm{~S}_{\mathrm{e}}$ & Energy cost share & .0148 & .0116 & .0124 & .0106 \\
$\mathrm{~S}_{\mathrm{m}}$ & Material cost share & .5478 & .1355 & .3983 & .1400 \\
$\mathrm{URB}$ & Population in shed & $1,253,120$ & $1,963,369$ & $4,911,588$ & $4,293,420$ \\
$\mathrm{LOC}$ & Industry employment in shed & 974 & 1,269 & 8,883 & 7,711 \\
& Employment & 95.4 & 283.3 & 98.92 & 243.83 \\
& Output per worker hour & 49.45 & 36.61 & 43.77 & 34.32 \\
& Capital to labor ratio & 19.06 & 13.12 & 14.53 & 13.77 \\
& Plant hourly wage & 13.05 & 5.08 & 15.24 & 5.64 \\
& Sample establishments & 863 & & 2,609 & \\
\hline
\end{tabular}

Source: Longitudinal Research Database (1992 Census of Manufactures). 
Table 2

Parameter estimates and asymptotic standard errors, Farm and garden machinery industry (SIC 352)

\begin{tabular}{|c|c|c|c|c|c|c|c|c|c|c|c|c|}
\hline \multirow[b]{2}{*}{ Parameter } & \multicolumn{3}{|c|}{ Nonhomotheticity } & \multicolumn{3}{|c|}{ Homotheticity } & \multicolumn{3}{|c|}{ Homogeneity } & \multicolumn{3}{|c|}{ Linear homogeneity } \\
\hline & $\begin{array}{c}\text { Estimat } \\
\mathrm{e}\end{array}$ & s.e. & t-stat & $\begin{array}{c}\text { Estimat } \\
\mathrm{e}\end{array}$ & s.e. & t-stat & $\begin{array}{c}\text { Estimat } \\
\mathrm{e}\end{array}$ & s.e. & t-stat & $\begin{array}{c}\text { Estimat } \\
\mathrm{e}\end{array}$ & s.e. & t-stat \\
\hline$\alpha_{0}$ & 2.9568 & 0.7984 & 3.70 & 2.6017 & 0.8024 & 3.24 & 2.5170 & 0.7433 & 3.39 & 2.5650 & 0.7443 & 3.45 \\
\hline$\alpha_{\mathrm{K}}$ & 0.0266 & 0.0055 & 4.83 & 0.0302 & 0.0053 & 5.65 & 0.0312 & 0.0042 & 7.46 & 0.0304 & 0.0041 & 7.40 \\
\hline$\alpha_{\mathrm{L}}$ & 0.7169 & 0.0381 & 18.84 & 0.7605 & 0.0376 & 20.23 & 0.7691 & 0.0275 & 28.02 & 0.7608 & 0.0269 & 28.31 \\
\hline$\alpha_{\mathrm{M}}$ & 0.1615 & 0.0448 & 3.60 & 0.2194 & 0.0431 & 5.09 & 0.2310 & 0.0249 & 9.29 & 0.2240 & 0.0244 & 9.18 \\
\hline$\alpha_{\mathrm{E}}$ & -0.0182 & 0.0035 & -5.22 & -0.0158 & 0.0034 & -4.57 & -0.0155 & 0.0033 & -4.67 & -0.0153 & 0.0033 & -4.68 \\
\hline$\beta_{\mathrm{KK}}$ & 0.0401 & 0.0006 & 64.38 & 0.0405 & 0.0006 & 66.42 & 0.0406 & 0.0006 & 67.34 & 0.0400 & 0.0005 & 73.89 \\
\hline$\beta_{\mathrm{KL}}$ & -0.0118 & 0.0007 & -17.21 & -0.0119 & 0.0006 & -19.14 & -0.0119 & 0.0006 & -19.27 & -0.0119 & 0.0006 & -19.53 \\
\hline$\beta_{\mathrm{KM}}$ & -0.0277 & 0.0006 & -44.14 & -0.0287 & 0.0006 & -49.28 & -0.0287 & 0.0006 & -49.37 & -0.0281 & 0.0005 & -53.33 \\
\hline$\beta_{\mathrm{KE}}$ & 0.0001 & 0.0003 & 0.17 & 0.0001 & 0.0003 & 0.21 & 0.0001 & 0.0003 & 0.20 & 0.0001 & 0.0003 & 0.18 \\
\hline$\beta_{\mathrm{LL}}$ & 0.1792 & 0.0047 & 38.16 & 0.1775 & 0.0034 & 51.56 & 0.1780 & 0.0034 & 52.14 & 0.1768 & 0.0033 & 53.22 \\
\hline$\beta_{\mathrm{LM}}$ & -0.1569 & 0.0036 & -43.71 & -0.1631 & 0.0031 & -52.74 & -0.1635 & 0.0031 & -53.25 & -0.1624 & 0.0030 & -54.43 \\
\hline$\beta_{\mathrm{LE}}$ & -0.0020 & 0.0005 & -3.79 & -0.0025 & 0.0005 & -5.34 & -0.0026 & 0.0005 & -5.38 & -0.0025 & 0.0005 & -5.41 \\
\hline$\beta_{\mathrm{EE}}$ & 0.0116 & 0.0004 & 32.29 & 0.0116 & 0.0004 & 32.23 & 0.0116 & 0.0004 & 32.38 & 0.0114 & 0.0003 & 33.02 \\
\hline$\beta_{\mathrm{EM}}$ & -0.0090 & 0.0004 & -20.59 & -0.0091 & 0.0004 & -21.22 & -0.0091 & 0.0004 & -21.22 & -0.0090 & 0.0004 & -21.46 \\
\hline$\beta_{\mathrm{MM}}$ & 0.2063 & 0.0031 & 66.34 & 0.2009 & 0.0030 & 67.71 & 0.2013 & 0.0029 & 68.56 & 0.1995 & 0.0028 & 71.62 \\
\hline$\xi_{\mathrm{P}}$ & -0.0474 & 0.1185 & -0.40 & -0.0250 & 0.1196 & -0.21 & -0.0267 & 0.1160 & -0.23 & -0.0268 & 0.1162 & -0.23 \\
\hline$\gamma_{\mathrm{KP}}$ & -0.0006 & 0.0004 & -1.43 & -0.0006 & 0.0004 & -1.59 & -0.0006 & 0.0003 & -2.02 & -0.0006 & 0.0003 & -2.05 \\
\hline$\gamma_{L P}$ & 0.0088 & 0.0027 & 3.19 & 0.0079 & 0.0028 & 2.86 & 0.0081 & 0.0020 & 4.02 & 0.0081 & 0.0020 & 4.06 \\
\hline$\gamma_{\mathrm{EP}}$ & 0.0011 & 0.0002 & 4.65 & 0.0011 & 0.0002 & 4.41 & 0.0011 & 0.0002 & 4.61 & 0.0011 & 0.0002 & 4.60 \\
\hline$\gamma_{M P}$ & -0.0079 & 0.0032 & -2.50 & -0.0087 & 0.0032 & -2.72 & -0.0086 & 0.0018 & -4.67 & -0.0086 & 0.0018 & -4.71 \\
\hline$\dot{\xi}_{\mathrm{C}}$ & -0.0067 & 0.0900 & -0.07 & -0.0490 & 0.0904 & -0.54 & -0.0399 & 0.0851 & -0.47 & -0.0292 & 0.0852 & -0.34 \\
\hline$\gamma_{\mathrm{KC}}$ & -0.0005 & 0.0004 & -1.52 & -0.0002 & 0.0003 & -0.69 & -0.0004 & 0.0003 & -1.61 & -0.0004 & 0.0003 & -1.57 \\
\hline$\gamma_{L C}$ & 0.0013 & 0.0027 & 0.48 & 0.0057 & 0.0024 & 2.35 & 0.0042 & 0.0018 & 2.37 & 0.0040 & 0.0018 & 2.29 \\
\hline$\gamma_{\mathrm{EC}}$ & -0.0006 & 0.0002 & -2.50 & -0.0003 & 0.0002 & -1.45 & -0.0004 & 0.0002 & -1.80 & -0.0004 & 0.0002 & -1.78 \\
\hline$\gamma_{\mathrm{MC}}$ & -0.0058 & 0.0029 & -2.02 & -0.0014 & 0.0027 & -0.51 & -0.0034 & 0.0016 & -2.11 & -0.0032 & 0.0016 & -2.03 \\
\hline$\delta_{\mathrm{PP}}$ & 0.0026 & 0.0097 & 0.26 & 0.0016 & 0.0098 & 0.16 & 0.0017 & 0.0098 & 0.18 & 0.0019 & 0.0098 & 0.19 \\
\hline$\delta_{\mathrm{PC}}$ & -0.0091 & 0.0080 & -1.14 & -0.0106 & 0.0080 & -1.33 & -0.0079 & 0.0074 & -1.06 & -0.0078 & 0.0074 & -1.05 \\
\hline$\delta_{\mathrm{CC}}$ & 0.0078 & 0.0067 & 1.17 & 0.0080 & 0.0068 & 1.18 & 0.0077 & 0.0064 & 1.20 & 0.0072 & 0.0064 & 1.13 \\
\hline$\theta$ & & & & & & & 1.0158 & 0.0062 & & & & \\
\hline $\mathrm{N}$ & & 863 & & & 863 & & & 863 & & & 863 & \\
\hline \multirow[t]{4}{*}{ Adj. $R^{21} s$} & Output & 0.969 & & & 0.969 & & & 0.969 & & & 0.968 & \\
\hline & $\mathrm{K}$ share & 0.838 & & & 0.837 & & & 0.837 & & & 0.837 & \\
\hline & L share & 0.710 & & & 0.708 & & & 0.708 & & & 0.707 & \\
\hline & M share & 0.797 & & & 0.796 & & & 0.796 & & & 0.796 & \\
\hline
\end{tabular}


Table 3

Parameter estimates and asymptotic standard errors, Measuring and controlling devices industry (SIC 382)

\begin{tabular}{|c|c|c|c|c|c|c|c|c|c|c|c|c|}
\hline \multirow[b]{2}{*}{ Parameter } & \multicolumn{3}{|c|}{ Nonhomotheticity } & \multicolumn{3}{|c|}{ Homotheticity } & \multicolumn{3}{|c|}{ Homogeneity } & \multicolumn{3}{|c|}{ Linear homogeneity } \\
\hline & $\begin{array}{c}\text { Estimat } \\
\mathrm{e}\end{array}$ & s.e. & t-stat & $\begin{array}{c}\text { Estimat } \\
\mathrm{e}\end{array}$ & s.e. & t-stat & $\begin{array}{c}\text { Estimat } \\
\mathrm{e}\end{array}$ & s.e. & t-stat & $\begin{array}{c}\text { Estimat } \\
\mathrm{e}\end{array}$ & s.e. & t-stat \\
\hline$\alpha_{0}$ & 2.2100 & 1.1621 & 1.90 & 2.7308 & 1.1580 & 2.36 & 1.8974 & 1.0706 & 1.77 & 2.1256 & 1.0729 & 1.98 \\
\hline$\alpha_{\mathrm{K}}$ & 0.0318 & 0.0116 & 2.74 & 0.0119 & 0.0111 & 1.08 & 0.0225 & 0.0097 & 2.32 & 0.0213 & 0.0095 & 2.24 \\
\hline$\alpha_{\mathrm{L}}$ & 0.8374 & 0.0406 & 20.61 & 0.7893 & 0.0384 & 20.53 & 0.8426 & 0.0255 & 33.02 & 0.8300 & 0.0250 & 33.22 \\
\hline$\alpha_{\mathrm{M}}$ & 0.1703 & 0.0323 & 5.27 & 0.1175 & 0.0304 & 3.86 & 0.1610 & 0.0208 & 7.73 & 0.1566 & 0.0205 & 7.65 \\
\hline$\alpha_{\mathrm{E}}$ & -0.0071 & 0.0033 & -2.16 & -0.0094 & 0.0031 & -2.98 & -0.0080 & 0.0031 & -2.60 & -0.0079 & 0.0030 & -2.62 \\
\hline$\beta_{\mathrm{KK}}$ & 0.0766 & 0.0008 & 100.74 & 0.0755 & 0.0007 & 102.29 & 0.0753 & 0.0007 & 102.14 & 0.0741 & 0.0007 & 109.12 \\
\hline$\beta_{\mathrm{KL}}$ & -0.0371 & 0.0009 & -39.69 & -0.0348 & 0.0008 & -42.54 & -0.0347 & 0.0008 & -42.40 & -0.0344 & 0.0008 & -42.95 \\
\hline$\beta_{\mathrm{KM}}$ & -0.0426 & 0.0007 & -60.88 & -0.0411 & 0.0007 & -63.23 & -0.0411 & 0.0007 & -63.14 & -0.0401 & 0.0006 & -66.05 \\
\hline$\beta_{\mathrm{KE}}$ & 0.0004 & 0.0002 & 1.70 & 0.0004 & 0.0002 & 1.92 & 0.0005 & 0.0002 & 1.97 & 0.0005 & 0.0002 & 1.99 \\
\hline$\beta_{\mathrm{LL}}$ & 0.1746 & 0.0028 & 62.85 & 0.1719 & 0.0020 & 86.22 & 0.1717 & 0.0020 & 86.24 & 0.1696 & 0.0019 & 88.41 \\
\hline$\beta_{\mathrm{LM}}$ & -0.1372 & 0.0019 & -73.75 & -0.1329 & 0.0016 & -84.47 & -0.1328 & 0.0016 & -84.55 & -0.1311 & 0.0015 & -86.81 \\
\hline$\beta_{\mathrm{LE}}$ & -0.0044 & 0.0003 & -14.13 & -0.0042 & 0.0003 & -15.09 & -0.0042 & 0.0003 & -15.09 & -0.0041 & 0.0003 & -15.18 \\
\hline$\beta_{\mathrm{EE}}$ & 0.0086 & 0.0002 & 38.76 & 0.0085 & 0.0002 & 39.11 & 0.0085 & 0.0002 & 39.13 & 0.0084 & 0.0002 & 39.55 \\
\hline$\beta_{\mathrm{EM}}$ & -0.0049 & 0.0002 & -20.49 & -0.0048 & 0.0002 & -20.26 & -0.0048 & 0.0002 & -20.33 & -0.0047 & 0.0002 & -20.34 \\
\hline$\beta_{\mathrm{MM}}$ & 0.1782 & 0.0015 & 115.06 & 0.1788 & 0.0015 & 117.75 & 0.1787 & 0.0015 & 117.85 & 0.1759 & 0.0014 & 127.03 \\
\hline$\xi_{\mathrm{P}}$ & 0.0201 & 0.2143 & 0.09 & -0.0055 & 0.2141 & -0.03 & 0.1233 & 0.2067 & 0.60 & 0.1055 & 0.2074 & 0.51 \\
\hline$\gamma_{\mathrm{KP}}$ & 0.0010 & 0.0010 & 1.00 & 0.0017 & 0.0010 & 1.64 & 0.0004 & 0.0009 & 0.41 & 0.0004 & 0.0009 & 0.40 \\
\hline$\gamma_{L P}$ & 0.0056 & 0.0037 & 1.53 & 0.0069 & 0.0036 & 1.90 & 0.0002 & 0.0024 & 0.07 & 0.0001 & 0.0023 & 0.06 \\
\hline$\gamma_{\mathrm{EP}}$ & 0.0003 & 0.0003 & 1.16 & 0.0004 & 0.0003 & 1.42 & 0.0002 & 0.0003 & 0.86 & 0.0002 & 0.0003 & 0.86 \\
\hline$\gamma_{\mathrm{MP}}$ & 0.0031 & 0.0029 & 1.06 & 0.0049 & 0.0029 & 1.68 & -0.0008 & 0.0019 & -0.39 & -0.0007 & 0.0019 & -0.39 \\
\hline$\xi_{\mathrm{C}}$ & 0.0504 & 0.1422 & 0.35 & 0.0625 & 0.1421 & 0.44 & -0.0421 & 0.1370 & -0.31 & -0.0365 & 0.1375 & -0.27 \\
\hline$\gamma_{\mathrm{KC}}$ & -0.0023 & 0.0007 & -3.09 & -0.0028 & 0.0007 & -3.81 & -0.0017 & 0.0006 & -2.71 & -0.0017 & 0.0006 & -2.71 \\
\hline$\gamma_{\mathrm{LC}}$ & 0.0042 & 0.0026 & 1.60 & 0.0029 & 0.0026 & 1.13 & 0.0084 & 0.0016 & 5.12 & 0.0083 & 0.0016 & 5.12 \\
\hline$\gamma_{\mathrm{EC}}$ & 0.0001 & 0.0002 & 0.27 & 0.0000 & 0.0002 & -0.05 & 0.0001 & 0.0002 & 0.66 & 0.0001 & 0.0002 & 0.66 \\
\hline$\gamma_{\mathrm{MC}}$ & -0.0103 & 0.0022 & -4.72 & -0.0117 & 0.0022 & -5.41 & -0.0069 & 0.0014 & -5.07 & -0.0068 & 0.0013 & -5.07 \\
\hline$\delta_{\mathrm{PP}}$ & -0.0053 & 0.0208 & -0.26 & -0.0053 & 0.0208 & -0.26 & -0.0117 & 0.0206 & -0.57 & -0.0111 & 0.0207 & -0.54 \\
\hline$\delta_{\mathrm{PC}}$ & 0.0069 & 0.0089 & 0.78 & 0.0073 & 0.0089 & 0.83 & 0.0020 & 0.0086 & 0.23 & 0.0004 & 0.0087 & 0.04 \\
\hline$\delta_{\mathrm{CC}}$ & -0.0012 & 0.0135 & -0.09 & -0.0009 & 0.0135 & -0.06 & 0.0046 & 0.0134 & 0.35 & 0.0053 & 0.0134 & 0.40 \\
\hline$\theta$ & & & & & & & 1.0181 & 0.0038 & 268.09 & & & \\
\hline $\mathrm{N}$ & & 2,609 & & & 2,609 & & & 2,609 & & & 2,609 & \\
\hline \multirow[t]{4}{*}{ Adj. $R^{21} s$} & Output & 0.957 & & & 0.957 & & & 0.957 & & & 0.957 & \\
\hline & K share & 0.780 & & & 0.780 & & & 0.779 & & & 0.779 & \\
\hline & L share & 0.683 & & & 0.688 & & & 0.688 & & & 0.687 & \\
\hline & M share & 0.827 & & & 0.826 & & & 0.827 & & & 0.826 & \\
\hline
\end{tabular}


Table 4

Likelihood ratio statistics, tests on restrictions

\begin{tabular}{lcccc}
\hline & SIC 352 & SIC 382 & $\begin{array}{c}95 \% \text { critical } \\
\text { value }\end{array}$ & $\begin{array}{c}99 \% \text { critical } \\
\text { value }\end{array}$ \\
\hline Technology Assumptions & & & & \\
$\quad$ Homotheticity & 7.80 & 8.88 & 9.49 & 13.28 \\
$\quad$ Homogeneity & 0.22 & 2.04 & 5.99 & 9.21 \\
$\quad$ Linear Homogeneity & 1.62 & 5.67 & 3.84 & 6.63 \\
Hicks-Neutrality & & & & \\
$\quad$ Urbanization & 12.80 & 1.07 & 9.49 & 13.28 \\
$\quad$ Localization & 2.23 & 7.94 & 9.49 & 13.28 \\
$\quad$ Urbanization/Localization & 15.62 & 28.82 & 15.51 & 20.09 \\
\hline
\end{tabular}

Note: Hicks-neutrality tests are conducted for non-homothetic model. 
Table 5

Output elasticities, internal economies, and agglomeration economies

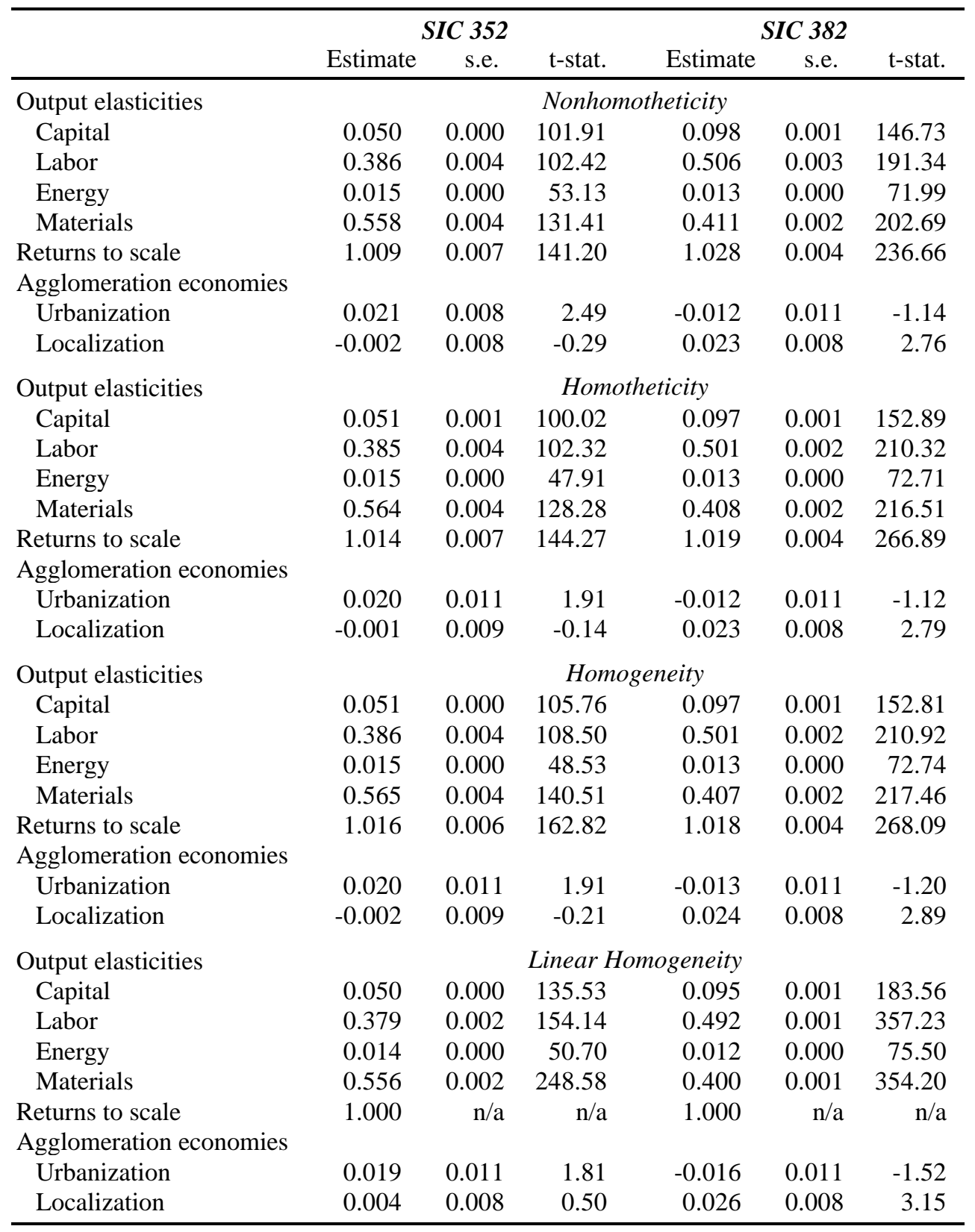

Note: Elasticities are evaluated at the sample means. 